ARTICLE

DOI: $10.1038 / \mathrm{s} 41467-018-04634-6$

\title{
Vapor transport deposition of antimony selenide thin film solar cells with $7.6 \%$ efficiency
}

\author{
Xixing Wen ${ }^{1,2}$, Chao Chen ${ }^{1,2}$, Shuaicheng Lu², ${ }^{1,2}$ Kanghua Li, ${ }^{1,2}$, Rokas Kondrotas ${ }^{1,2}$, Yang Zhao ${ }^{1,2}$, \\ Wenhao Chen ${ }^{1,2}$, Liang Gao ${ }^{1,2}$, Chong Wang ${ }^{1,2}$, Jun Zhang ${ }^{1,2}$, Guangda Niu',2 \& Jiang Tang (1) 1,2
}

Antimony selenide is an emerging promising thin film photovoltaic material thanks to its binary composition, suitable bandgap, high absorption coefficient, inert grain boundaries and earth-abundant constituents. However, current devices produced from rapid thermal evaporation strategy suffer from low-quality film and unsatisfactory performance. Herein, we develop a vapor transport deposition technique to fabricate antimony selenide films, a technique that enables continuous and low-cost manufacturing of cadmium telluride solar cells. We improve the crystallinity of antimony selenide films and then successfully produce superstrate cadmium sulfide/antimony selenide solar cells with a certified power conversion efficiency of $7.6 \%$, a net $2 \%$ improvement over previous $5.6 \%$ record of the same device configuration. We analyze the deep defects in antimony selenide solar cells, and find that the density of the dominant deep defects is reduced by one order of magnitude using vapor transport deposition process.

\footnotetext{
${ }^{1}$ Sargent Joint Research Center, Wuhan National Laboratory for Optoelectronics and School of Optical and Electronic Information, Huazhong University of Science and Technology, 1037 Luoyu Road, Wuhan 430074, Hubei, China. ${ }^{2}$ Shenzhen R\&D Center of Huazhong University of Science and Technology, Shenzhen 518000, China. Correspondence and requests for materials should be addressed to J.T. (email: jtang@mail.hust.edu.cn)
} 
A ntimony selenide $\left(\mathrm{Sb}_{2} \mathrm{Se}_{3}\right)$ has recently emerged as a promising green alternative to CdTe solar cells because it possesses very attractive optoelectronic properties such as proper bandgap (about $1.03 \mathrm{eV}$ indirect and $1.17 \mathrm{eV}$ direct) for the absorption of a significant portion of the solar spectrum, high optical absorption coefficient (greater than $10^{5} \mathrm{~cm}^{-1}$ ) and decent carrier mobility (about $\left.10 \mathrm{~cm}^{2} \mathrm{~V}^{-1} \mathrm{~s}^{-1}\right)^{1-3}$. Besides, because it is a binary compound with high vapor pressure, a fast, low temperature vacuum-based deposition technique can be employed like the ones established in CdTe photovoltaics. It also possesses a one-dimensional crystal structure with loose van der Waals interaction between ribbons ${ }^{1}$, thereby enabling grain boundaries free of dangling bonds in $c$-axis-oriented films and minimizing recombination losses therein. Furthermore, the earth-abundant elemental compositions of $\mathrm{Sb}_{2} \mathrm{Se}_{3}$ as well as its easy fabrication promise low-cost manufacturing. All these attributes suggest the great potential of $\mathrm{Sb}_{2} \mathrm{Se}_{3}$ for high-efficiency thin film solar cell and commercial application.

However, the highest power conversion efficiency (PCE) of $\mathrm{Sb}_{2} \mathrm{Se}_{3}$ thin film solar cells with a $\mathrm{CdS} / \mathrm{Sb}_{2} \mathrm{Se}_{3}$ superstrate configuration is so far $5.6 \%{ }^{2,4-11}$, and with a $\mathrm{ZnO} / \mathrm{Sb}_{2} \mathrm{Se}_{3}$ superstrate configuration $5.93 \%{ }^{1}$. Employing $\mathrm{PbS}$ colloidal quantum dots (QDs) as the hole transport layer, as-fabricated device CdS/ $\mathrm{Sb}_{2} \mathrm{Se}_{3} / \mathrm{PbS}$ QDs demonstrated an efficiency of $6.5 \%{ }^{12}$. Rapid thermal evaporation (RTE) was used to fabricate all abovementioned $\mathrm{Sb}_{2} \mathrm{Se}_{3}$ solar cells. RTE is a process similar to closespace sublimation ${ }^{2}$, in which the vapor is limited to a confined space and rapidly deposits on the substrate. The distance from the substrate to the evaporation source is only $0.8 \mathrm{~cm}$, and the whole deposition is performed within $35 \mathrm{~s}$. The small confined space and the rapid deposition increase the difficulty of mixing the vapor particles ( $\mathrm{Se}, \mathrm{Sb}$ and $\mathrm{Sb}_{x} \mathrm{Se}_{y}$ ) evenly, potentially promoting defect formation. The formation of defects, such as interstitial and antisite defects, accelerates nonradiative recombination and degrades device performance ${ }^{13-16}$. Furthermore, limited by our RTE facility, a simple one-zone tube furnace, the source and substrate temperatures are strongly correlated, which seriously hinders the independent optimization of both substrate and source temperature. These problems in our RTE technique have seriously restricted the development of $\mathrm{Sb}_{2} \mathrm{Se}_{3}$ solar cells. Therefore, we urgently need to explore alternative strategies to further improve $\mathrm{Sb}_{2} \mathrm{Se}_{3}$ film quality and device performance.

Here, we develop a vapor transport deposition (VTD) process to fabricate record efficiency $\mathrm{Sb}_{2} \mathrm{Se}_{3}$ thin film solar cells. In the VTD process, both the substrate temperature and the distance between source and substrate are adjustable, enabling not only highly oriented $\mathrm{Sb}_{2} \mathrm{Se}_{3}$ film, but also enormously improved film crystallinity and reduced bulk and interfacial defects in $\mathrm{Sb}_{2} \mathrm{Se}_{3}$ solar cells. In addition, the VTD process is a proven low-cost and fast-turnaround manufacturing method for commercial CdTe solar cells ${ }^{17,18}$, and adopting this technique for $\mathrm{Sb}_{2} \mathrm{Se}_{3}$ technology could facilitate the commercial competitiveness of $\mathrm{Sb}_{2} \mathrm{Se}_{3}$ solar cells. After optimizing the $\mathrm{Sb}_{2} \mathrm{Se}_{3}$ films via VTD process, we obtain the champion indium tin oxide (ITO)/CdS/Sb $\mathrm{Se}_{3} / \mathrm{Au}$ solar cells with a certified efficiency of $7.6 \%$, which is a record of all $\mathrm{Sb}_{2} \mathrm{Se}_{3}$ thin film solar cells by far $1,2,4-12,19,20$ and represents a net $2 \%$ efficiency gain over previous report with the same device configuration $^{2}$. We comparatively analyze the physical properties of VTD-fabricated and RTE-fabricated $\mathrm{Sb}_{2} \mathrm{Se}_{3}$ devices by X-ray diffraction (XRD), transient absorption (TA) spectroscopy and deep-level transient spectroscopy (DLTS). We find that the VTDfabricated devices possess much higher film crystallinity, longer carrier lifetime and fewer bulk and interfacial defects than RTEfabricated devices. Especially, the reduced density of defect complex $\left(\mathrm{Sb}_{\mathrm{Se}}+\mathrm{Se}_{\mathrm{Sb}}\right)$ enhances the device performance by decreasing the photo-generated carrier recombination.

\section{Results}

Fabrication of $\mathrm{Sb}_{2} \mathrm{Se}_{3}$ films via VTD process. A schematic representation of VTD system is shown in Fig. 1a. The $\mathrm{Sb}_{2} \mathrm{Se}_{3}$ powder and the substrate were placed in the center and at the right end of the heater, respectively. The full deposition details are provided in experimental section. Hereby, the heating temperature of the evaporation source, the pressure in quartz tube and the substrate temperature are the key factors that determining the quality of final $\mathrm{Sb}_{2} \mathrm{Se}_{3}$ films. The distance between the substrate and the heating center was varied to achieve adjustable substrate temperature. We deposited $\mathrm{Sb}_{2} \mathrm{Se}_{3}$ films at different heating temperatures, pressures and substrate temperatures. XRDs of all $\mathrm{Sb}_{2} \mathrm{Se}_{3}$ films were measured to characterize the crystallinity and orientation of these films, which is shown in Supplementary Fig. 1. All the $\mathrm{Sb}_{2} \mathrm{Se}_{3}$ films had a preferred [221] orientation with the only difference being the intensity of the diffraction peaks. As $\mathrm{Sb}_{2} \mathrm{Se}_{3}$ is composed of one-dimensional $\left(\mathrm{Sb}_{4} \mathrm{Se}_{6}\right)_{n}$ ribbons stacking together via weak van der Waals force, a proper film orientation is crucial for facile carrier transport in the film ${ }^{1,2}$. Our previous reports have demonstrated that [221]-orientation enhances carrier transport across $\mathrm{Sb}_{2} \mathrm{Se}_{3}$ film ${ }^{1,2,6,8}$. Therefore, with the film thickness and measurement details kept strictly identical, we utilized the intensity of (221) XRD peaks in $\mathrm{Sb}_{2} \mathrm{Se}_{3}$ films to evaluate their crystallinity. The crystallinity evolution of $\mathrm{Sb}_{2} \mathrm{Se}_{3}$ films deposited on CdS layers with varied evaporation temperature, pressure and distance was investigated, as shown in Fig. 1b. By carefully optimizing the three key factors, $\mathrm{Sb}_{2} \mathrm{Se}_{3}$ film with the highest crystallinity was obtained when the evaporating temperature was set at $510^{\circ} \mathrm{C}$, the pressure was $3.2 \mathrm{~Pa}$ and the distance from the substrate to the heating center was $21 \mathrm{~cm}$. Here, the actual temperature curves of powder and substrate were a

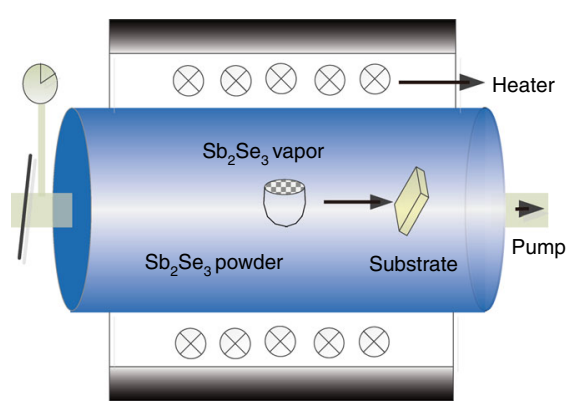

b

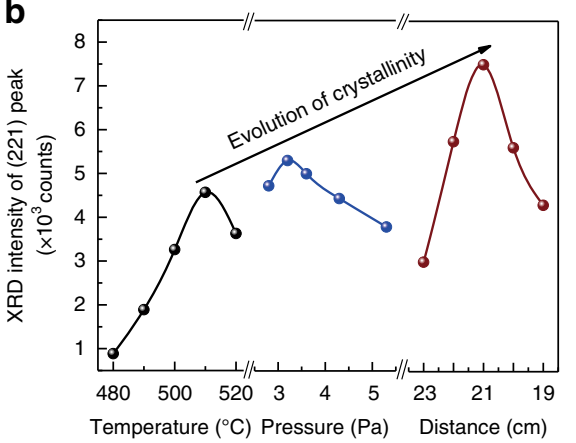

C

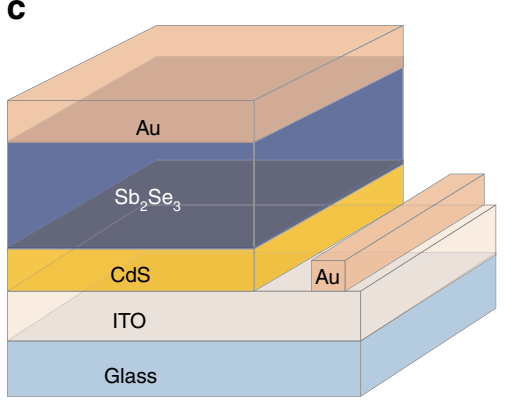

Fig. 1 Fabrication of $\mathrm{CdS} / \mathrm{Sb}_{2} \mathrm{Se}_{3}$ solar cells. a Schematics of our VTD system. $\mathbf{b}$ Evolution of crystallinity with the optimization of deposition condition. $\mathbf{c}$ The device structure of our $\mathrm{Sb}_{2} \mathrm{Se}_{3}$ solar cells 

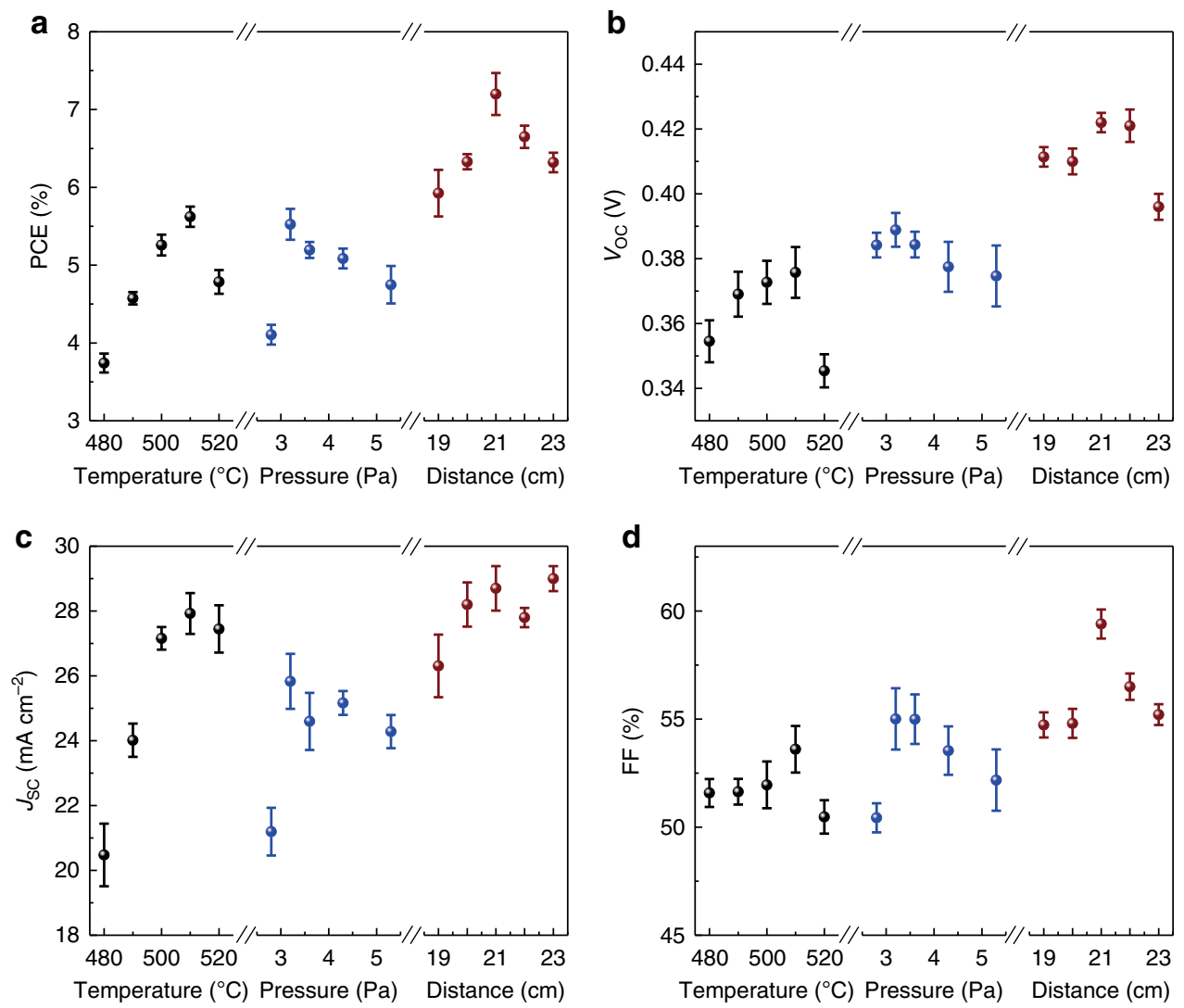

Fig. 2 Deposition condition-dependent photovoltaic characteristics. a Power conversion efficiency (PCE), b open-circuit voltage ( $\left.V_{O C}\right)$, c short-circuit current density $\left(J_{S C}\right)$ and $\mathbf{d}$ fill factor $(F F)$ of the $\mathrm{CdS} / \mathrm{Sb}_{2} \mathrm{Se}_{3}$ solar cells fabricated by VTD process. A total of 135 devices are included for the statistics analysis. Solid sphere symbols and error bars indicate average values and standard deviations, respectively

monitored during the heating and cooling steps. The input temperature program and the measured temperature curves of substrate and powder are shown in Supplementary Fig. 2. This heating profile and substrate distance corresponded to the maximum actual source and substrate temperatures of $540{ }^{\circ} \mathrm{C}$ and $390^{\circ} \mathrm{C}$, respectively, as monitored by the thermocouples.

The crystallinity evolution of $\mathrm{Sb}_{2} \mathrm{Se}_{3}$ films indicates the importance of evaporation temperature, pressure and substrate temperature in VTD process. High evaporation temperature increases the kinetic energy of vapor particles and the surface mobility of adatoms on the substrate ${ }^{21}$. On the other hand, high pressure can increase in-flight collisions with background gas atoms, and then reduced the kinetic energy of vapor particles ${ }^{21,22}$. In addition, increasing the substrate temperature will lead to the increased surface mobility of adatoms ${ }^{22}$. Hence, the kinetic energy of vapor particles and surface mobility of adatoms are ultimately defined by combination of evaporation temperature, pressure and substrate temperature. During the $\mathrm{Sb}_{2} \mathrm{Se}_{3}$ film deposition, vapor particles with proper kinetic energy and adatoms with proper surface mobility are mandatory for highquality $\mathrm{Sb}_{2} \mathrm{Se}_{3}$ films. Energetic vapor particles and high mobility of adatoms may increase the instability of adatoms, causing displacements of lattice and consequently creating lattice defects ${ }^{21}, 22$. Such defects may act as new nucleation sites and increase nucleation density of adatoms ${ }^{22}$. In the extreme, the increased lattice defects and nucleation density may result in decreased crystallinity and quality of the film. That is why the crystallinity of the $\mathrm{Sb}_{2} \mathrm{Se}_{3}$ film decreased when deposited at overly high evaporation temperature, lower pressure and closer distance to evaporation source.
Device performance. The $\mathrm{Sb}_{2} \mathrm{Se}_{3}$ absorber layers were fabricated under the above-mentioned conditions, and the corresponding device structure ITO/CdS/ $\mathrm{Sb}_{2} \mathrm{Se}_{3} / \mathrm{Au}$ is shown in Fig. 1c. The dependence of device performance on different evaporation temperatures, pressures and distances is summarized in Fig. 2. The variation trend of PCE is similar to the crystallinity evolution of $\mathrm{Sb}_{2} \mathrm{Se}_{3}$ films (Fig. 1b), which indicates that device performance strongly correlates with the crystallinity of $\mathrm{Sb}_{2} \mathrm{Se}_{3}$ film. As can be seen from Fig. 2, the best PCE, open-circuit voltage $\left(V_{\mathrm{OC}}\right)$, shortcircuit current density $\left(J_{\mathrm{SC}}\right)$ and fill factor $(\mathrm{FF})$ were obtained under the deposition condition where the highest film crystallinity was achieved (Fig. 1b). After carefully optimizing $\mathrm{Sb}_{2} \mathrm{Se}_{3}$ films and devices, the champion device with a certified power conversion efficiency of $7.6 \%$ was obtained (certificate included in Supplementary Fig. 3). This value represents the highest PCE of all $\mathrm{Sb}_{2} \mathrm{Se}_{3}$ thin film solar cells reported so far ${ }^{1,2,4-12}$, which is $2 \%$ higher than previous $5.6 \%$ certified efficiency with the same device configuration ${ }^{2}$. Figure 3 a shows the light current densityvoltage $(J-V)$ curve of the champion VTD-fabricated $\mathrm{CdS} / \mathrm{Sb}_{2} \mathrm{Se}_{3}$ solar cell with certified PCE of $7.6 \%, V_{\mathrm{OC}}$ of $0.42 \mathrm{~V}, J_{\mathrm{SC}}$ of 29.9 $\mathrm{mA} \mathrm{cm}{ }^{-2}$ and $\mathrm{FF}$ of $60.4 \%$. The $J-V$ curve of a RTE-fabricated solar cell with PCE of $5.6 \%\left(V_{\mathrm{OC}}=0.39 \mathrm{~V}, J_{\mathrm{SC}}=25.3 \mathrm{~mA} \mathrm{~cm}^{-2}\right.$ and $\mathrm{FF}=56.4 \%$ ) is also included in Fig. 3a for comparison. Obviously, every performance parameter of the VTD-fabricated solar cell, especially $J_{\mathrm{SC}}$, is larger than that of the RTE-fabricated device.

We further checked the external quantum efficiency (EQE) of the two devices (Fig. 3b) to investigate their photo-response. The EQE spectrum of VTD-fabricated device demonstrated a higher photo-response from $520 \mathrm{~nm}$ (the absorption onset of CdS layer) 

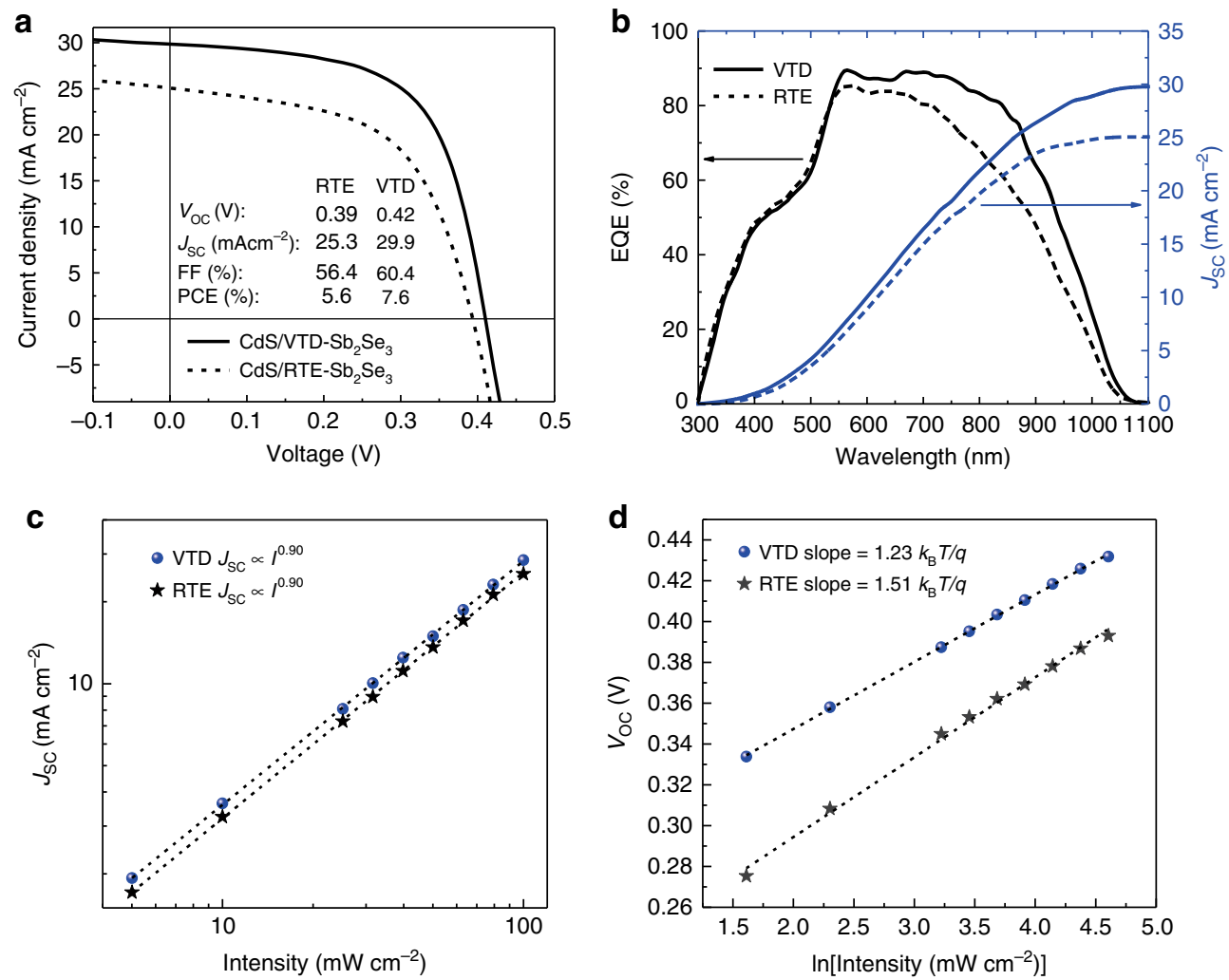

Fig. 3 Device performance and light intensity-dependent $J_{S C}$ and $V_{O C}$ of devices. a The light J-V curves of VTD-and RTE-fabricated devices under AM1.5 G illumination. The $J-V$ curve of the VTD-fabricated device with certified efficiency of $7.6 \%$ (area $=0.091 \mathrm{~cm}^{2}$ ) was measured by National Institute of Metrology on 1 September 2017. The calibration certificate number is GXtc2017-1987 (Supplementary Fig. 3). b EQE and integrated JSC of the VTD- and RTE-fabricated devices. Light intensity-dependent $\mathbf{c} J_{S C}$ and $\mathbf{d} V_{O C}$. Neutral-density filters (THORLABS) were used to control the light intensity

to $1100 \mathrm{~nm}$ than that of RTE-fabricated device. The maximum EQE of VTD-fabricated device was close to $90 \%$ between 540 and $720 \mathrm{~nm}$. For comparison, the device fabricated by our RTE technique only had the maximum EQE of about $85 \%$. This suggests the VTD-fabricated devices possess very low recombination losses of photo-generated carriers and long carrier lifetimes at $\mathrm{CdS} / \mathrm{Sb}_{2} \mathrm{Se}_{3}$ interface and in the whole $\mathrm{Sb}_{2} \mathrm{Se}_{3}$ absorber ${ }^{23}$. In Fig. 3b, we derived the current density of 29.8 and $25.1 \mathrm{~mA} \mathrm{~cm}^{-2}$ by integrating the EQE spectra with standard AM1.5 spectrum to further validate our $J_{\mathrm{SC}}$ values, which agreed with the experimental values of 29.9 and $25.3 \mathrm{~mA} \mathrm{~cm}^{-2}$ very well, respectively. Furthermore, a solar cell with initial PCE of $7.25 \%$ was stored in ambient air for about 40 days without encapsulation. This representative device was measured every week to monitor the stability of $\mathrm{Sb}_{2} \mathrm{Se}_{3}$ film solar cell, and the results are displayed in Supplementary Fig. 4a. The PCE remained unchanged during the whole process. For the stability of device under continuous illumination, Supplementary Fig. $4 \mathrm{~b}$ shows slight decrease for $\mathrm{CdS} / \mathrm{Sb}_{2} \mathrm{Se}_{3}$ device but no decrease for $\mathrm{ZnO} / \mathrm{Sb}_{2} \mathrm{Se}_{3}$ device, which is consistent with the previous report ${ }^{1}$. These results indicate that VTD process is a simple and effective technique for producing high-efficiency and stable $\mathrm{Sb}_{2} \mathrm{Se}_{3}$ thin film solar cells.

Carrier recombination in $\mathrm{CdS} / \mathrm{Sb}_{2} \mathrm{Se}_{3}$ solar cells. From the improved EQE of VTD-fabricated devices, we inferred that the carrier transport was enhanced, and recombination loss was reduced in the active $\mathrm{Sb}_{2} \mathrm{Se}_{3}$ layer by VTD process. Therefore, to further clarify the carrier recombination processes in $\mathrm{Sb}_{2} \mathrm{Se}_{3}$ solar cells, we performed light-intensity-dependent $J_{\mathrm{SC}}$ and $V_{\mathrm{OC}}$ measurements on the VTD- and RTE-based photovoltaic devices. The complete sets of $J-V$ curves are given in Supplementary Fig. 5.
Figure $3 \mathrm{c}$ illustrates $J_{\mathrm{SC}}$ as a function of light intensity $(I)$. Herein, $J_{\text {SC }}$ was fitted according to the power law dependence $\left(J_{\text {SC }} \propto I^{\alpha}\right)$ by the $\log -\log$ scale plot. The power value $\alpha$ for both devices is 0.9 , close to unity (first-order). This means that trap-assisted recombination is present in both solar cells and is the dominating loss mechanism ${ }^{24}, 25$. The light-intensity-dependent $V_{\mathrm{OC}}$ can provide critical insights into the recombination mechanism in the solar cells ${ }^{26}$. For $V_{\mathrm{OC}}$ measurement, the device is open circuit, so there is no current extraction from the devices, and all photogenerated carriers recombine in $\mathrm{Sb}_{2} \mathrm{Se}_{3}$ film. Thus, the carrier recombination process can be reflected based on the relationship of $V_{\mathrm{OC}} \propto n\left(k_{\mathrm{B}} T / q\right) \ln (I)$, where $k_{\mathrm{B}}$ is the Boltzmann constant, $T$ is the temperature and $q$ is elementary charge ${ }^{26-29} \cdot n\left(k_{\mathrm{B}} T / q\right)$ is the slope of $V_{\mathrm{OC}}$ vs. the natural logarithm of light-intensity $\ln (I)$. For trap-free solar cells, the slope of $V_{\mathrm{OC}}$ vs. $\ln (I)$ should be $k_{\mathrm{B}} T / q$ (i.e., $n=1)^{26,29}$. For our devices, as shown in Fig. $3 \mathrm{~d}$, the slopes obtained by linear fitting were $1.23\left(k_{\mathrm{B}} T / q\right)$ for the VTDfabricated device and $1.51\left(k_{\mathrm{B}} T / q\right)$ for the RTE-fabricated device. This, again, indicates the presence of trap-assisted Shockley-Read-Hall (SRH) recombination in both devices 29,30 . The slope was decreased from $1.51\left(k_{\mathrm{B}} T / q\right)$ to $1.23\left(k_{\mathrm{B}} T / q\right)$ by using VTD process, suggesting reduced trap-assisted recombination in VTD-fabricated devices ${ }^{28,31}$. We measured the TA decay of the two devices to investigate the carrier lifetime (Supplementary Fig. 6). For the steady-state absorption (Supplementary Fig. 7) of VTD- and RTE-fabricated $\mathrm{Sb}_{2} \mathrm{Se}_{3}$ films, the absorption rose to the maximum at around $940 \mathrm{~nm}$. Thus, the transient kinetic decay was monitored at $940 \mathrm{~nm}$. By fitting the kinetic decay data, the longer carrier lifetime (1339 ps) was obtained in VTD-fabricated device than that (1149 ps) of RTE-derived device. Longer carrier lifetime not only permits more efficient carrier collection and hence larger $J_{\mathrm{SC}}\left(\mathrm{VTD} 29.9 \mathrm{~mA} \mathrm{~cm}^{-2}\right.$ vs. RTE $25.3 \mathrm{~mA} \mathrm{~cm}^{-2}$ ), 


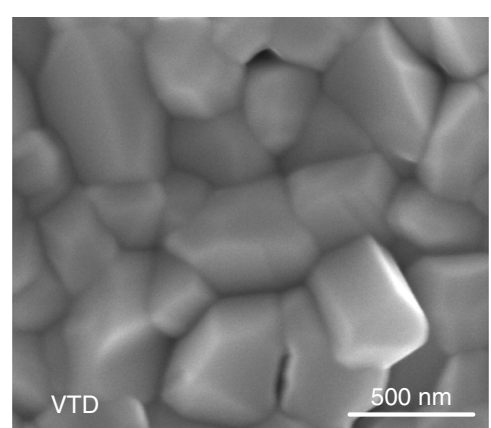

d

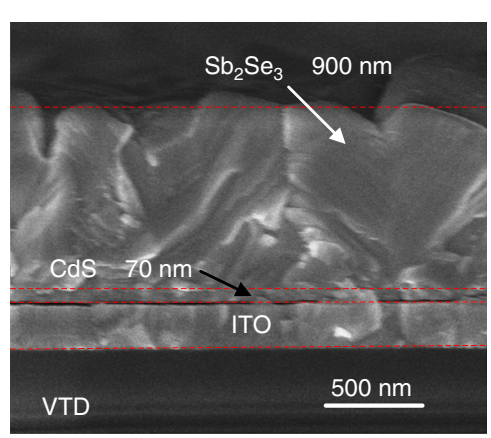

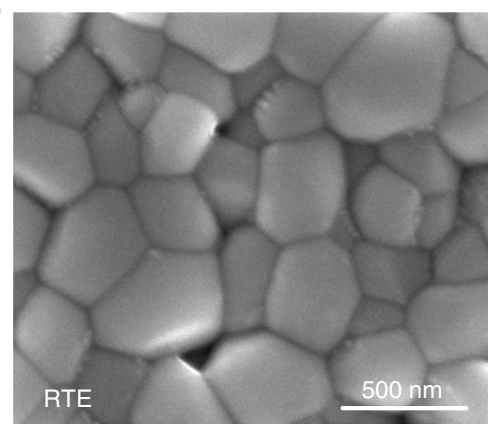

$\mathbf{e}$

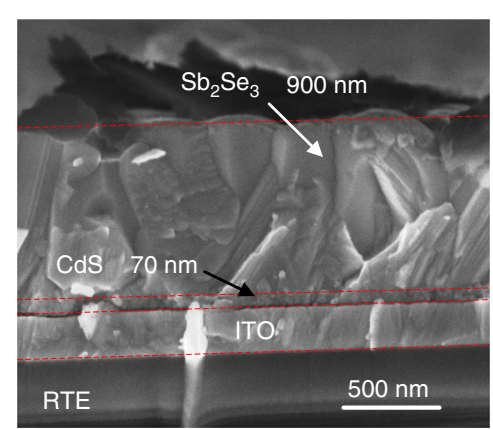

C

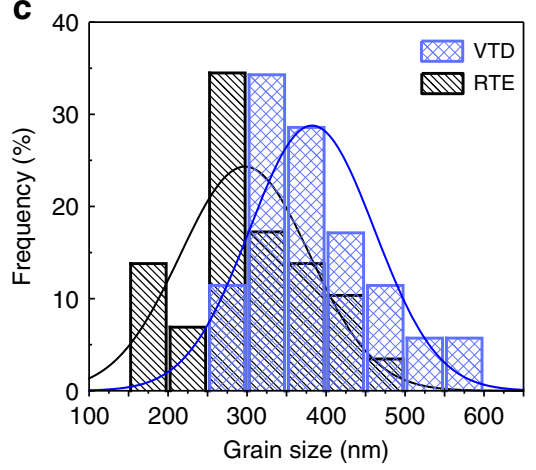

f

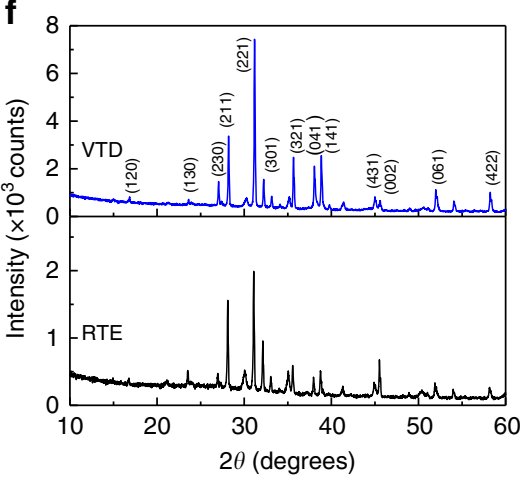

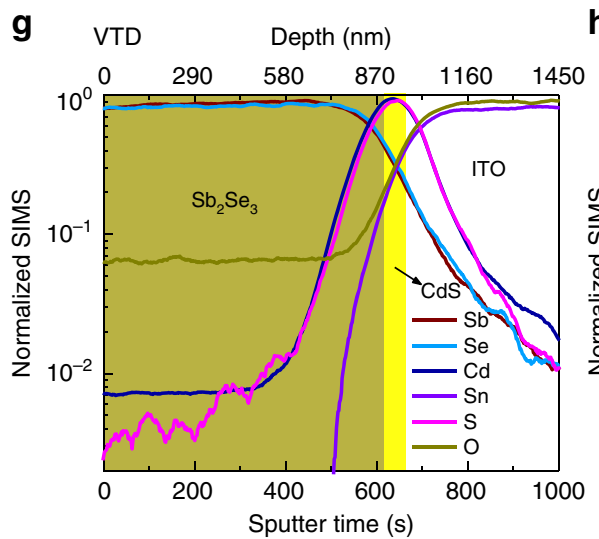

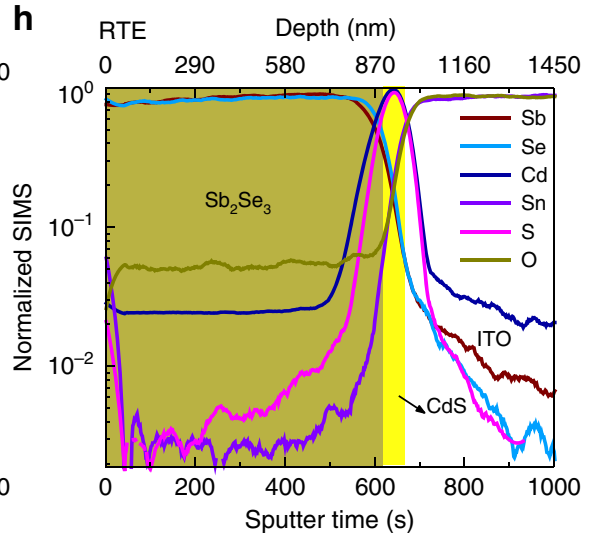

i

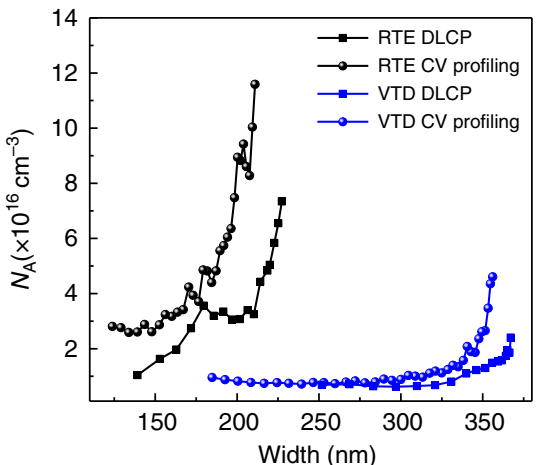

Fig. 4 Characterization of $\mathrm{Sb}_{2} \mathrm{Se}_{3}$ films and interface analysis of $\mathrm{CdS} / \mathrm{Sb}_{2} \mathrm{Se}_{3}$ devices. SEM top-view images of a VTD-fabricated and $\mathbf{b}$ RTE-fabricated $\mathrm{Sb}_{2} \mathrm{Se}_{3}$ films. c Histogram of grain size in VTD-fabricated and RTE-fabricated $\mathrm{Sb}_{2} \mathrm{Se}_{3}$ films. Cross-sectional SEM images of $\mathbf{d}$ VTD-fabricated and e RTEfabricated $\mathrm{CdS} / \mathrm{Sb}_{2} \mathrm{Se}_{3}$ devices. $\mathbf{f}$ XRD of VTD-fabricated and RTE-fabricated $\mathrm{Sb}_{2} \mathrm{Se}_{3}$ films. SIMS depth analysis of $\mathbf{g}$ VTD-fabricated and $\mathbf{h}$ RTE-fabricated devices. i C-V profiling and DLCP for VTD- and RTE-fabricated devices

but also enables higher carrier concentration within the absorber layer and therefore wider quasi-Fermi level splitting and improved $V_{\text {OC }}$ (VTD $0.42 \mathrm{~V}$ vs. RTE $0.39 \mathrm{~V}$ ).

Morphology and crystallization of $\mathrm{Sb}_{2} \mathrm{Se}_{3}$ films. We now study the material origin of the improved device performance. The scanning electron microscopy (SEM) top view images of $\mathrm{Sb}_{2} \mathrm{Se}_{3}$ films deposited on glass/ITO/CdS substrates by VTD and RTE are shown in Fig. $4 a, b$, respectively. The grains of VTDfabricated film are obviously larger than that of $\mathrm{Sb}_{2} \mathrm{Se}_{3}$ film from RTE process. We statistically analyzed the distribution of grain size from the two SEM top view images. Figure $4 \mathrm{c}$ depicts the histograms of the grain size. The average grain size of VTDfabricated film was $382 \mathrm{~nm}$ with a standard deviation of $79 \mathrm{~nm}$, whereas the RTE-derived $\mathrm{Sb}_{2} \mathrm{Se}_{3}$ film had an average size of 297 $\mathrm{nm}$ and a standard deviation of $82 \mathrm{~nm}$. The cross-sectional SEM images of $\mathrm{Sb}_{2} \mathrm{Se}_{3}$ solar cells fabricated by VTD and RTE methods are shown in Fig. 4d, e, respectively. Device structures in both cases were the same: ITO/CdS/Sb $\mathrm{Se}_{3} / \mathrm{Au}$. The $\mathrm{Sb}_{2} \mathrm{Se}_{3}$ layers were compact and well adherent to the CdS with the same thickness of about $900 \mathrm{~nm}$. We compared XRD patterns of the two $\mathrm{Sb}_{2} \mathrm{Se}_{3}$ layers, measured under identical conditions, as shown in Fig. $4 \mathrm{f}$. Obviously, both films were favorably orientated along [221] direction. However, the XRD intensity of VTD-fabricated film was much stronger than that of RTE-fabricated film, indicating much higher crystallinity was obtained by VTD process. The SEM and XRD results both demonstrate VTD-fabricated $\mathrm{Sb}_{2} \mathrm{Se}_{3}$ films have larger grains and higher crystallinity compared with RTEfabricated films. It should be noted that, for RTE-fabricated $\mathrm{Sb}_{2} \mathrm{Se}_{3}$ film, the distance between evaporation source and substrate was merely $0.8 \mathrm{~cm}$, and the deposition was carried out on $350{ }^{\circ} \mathrm{C}$ substrate for $35 \mathrm{~s}^{1,2}$, while the corresponding value in the VTD process was $21 \mathrm{~cm}, 390^{\circ} \mathrm{C}$ and $2 \mathrm{~min}$, respectively. Longer traveling distance could increase the collision probability between $\mathrm{Sb}_{x} \mathrm{Se}_{y}$ particles and gas molecules, reduce the momentum of these particles when impinge onto the substrate and hence 
decrease the occurrence of nucleation. Less nucleus within the film, accompanied with higher substrate temperature and longer film growth duration, enabled the VTD-derived $\mathrm{Sb}_{2} \mathrm{Se}_{3}$ film with larger grain size and better grain crystallinity ${ }^{21}$.

Interfacial properties of the devices. For all thin film photovoltaic devices with $\mathrm{CdS}$ as buffer layer, $\mathrm{Cd}$ diffusion at the interface is always observed ${ }^{32,33}$. To check the Cd diffusion in our devices, we measured their composition distribution by secondary ion mass spectroscopy (SIMS) depth profiling. As shown in Fig. 4g, $\mathrm{h}$, Cd diffusion was observed in both VTD-fabricated and RTEfabricated $\mathrm{CdS} / \mathrm{Sb}_{2} \mathrm{Se}_{3}$ devices. The deeper $\mathrm{Cd}$ diffusion (greater than $200 \mathrm{~nm}$ ) than that (greater than $100 \mathrm{~nm}$ ) in RTE-fabricated device was found in VTD-fabricated device. As CdS buffer layer was prepared following identical procedures, we deduced that the different Cd-diffused depth was certainly caused by the different deposition techniques: for VTD process, substrate temperature was about $390^{\circ} \mathrm{C}$ and deposition lasted for $2 \mathrm{~min}$, while in RTE process the corresponding values were $350^{\circ} \mathrm{C}$ and $35 \mathrm{~s}$, respectively ${ }^{1,2}$. Because diffusion is driven thermally, higher substrate temperature and longer deposition time resulted in more Cd diffusion in VTDfabricated device. As we reported before ${ }^{32}$, Cd diffusion converted p-type $\mathrm{Sb}_{2} \mathrm{Se}_{3}$ into n-type, and resulted in a buried homojunction at $\mathrm{CdS} / \mathrm{Sb}_{2} \mathrm{Se}_{3}$ interface. This could reduce the interface defects and recombination at the heterojunction interface ${ }^{34}$, being beneficial for device performance.

Therefore, we further measured interfacial defects using capacitance-voltage $(C-V)$ profiling and deep-level capacitance profiling (DLCP) techniques $1,35,36$. Generally, the defects density obtained from $C-V$ profiling $\left(N_{\mathrm{CV}}\right)$ includes the response of free carriers, and bulk and interfacial defects, while the defect density obtained from DLCP measurement $\left(N_{\mathrm{DLCP}}\right)$ represents the response only from the free carrier and the bulk defects ${ }^{1,} 36$. Thus, we can characterize the defect density at $\mathrm{CdS} / \mathrm{Sb}_{2} \mathrm{Se}_{3}$ interface by the difference between $N_{\mathrm{CV}}$ and $N_{\mathrm{DLCP}}$. As shown in Fig. $4 \mathrm{i}$, obviously, the difference between $N_{\mathrm{CV}}$ and $N_{\text {DLCP }}$ of RTEfabricated device is much higher than that of VTD-fabricated device, indicating lower defect density at VTD-fabricated CdS/ $\mathrm{Sb}_{2} \mathrm{Se}_{3}$ interface. Because the doping concentration of $\mathrm{CdS}$ was much higher than in $\mathrm{Sb}_{2} \mathrm{Se}_{3}$ film ${ }^{3}, 6$, almost all depletion width $\left(W_{\mathrm{d}}\right)$ extended in $\mathrm{Sb}_{2} \mathrm{Se}_{3}$ layer. Here the volume to surface ratio is $W_{\mathrm{d}}$, the interfacial defect density of RTE-fabricated and VTDfabricated devices was calculated to be about $2.1 \times 10^{11} \mathrm{~cm}^{-2}$ and $2.8 \times 10^{10} \mathrm{~cm}^{-2}$, respectively. The interfacial defect density in VTD-fabricated $\mathrm{Sb}_{2} \mathrm{Se}_{3}$ solar cell is also much lower than that $\left(1.22 \times 10^{11} \mathrm{~cm}^{-2}\right)$ in RTE-fabricated $\mathrm{Sb}_{2} \mathrm{Se}_{3}$ solar cell with $\mathrm{ZnO}$ as buffer layer ${ }^{1}$. Consequently, we concluded that the promoted interfacial diffusion had effectively reduced interface defects. This is reminiscent of our previous observation that the performance of RTE-fabricated and thermally evaporated $\mathrm{CdS} / \mathrm{Sb}_{2} \mathrm{Se}_{3}$ solar cells always improved when stored in ambient air for a few days $^{2,6}$. Similar effect has also been demonstrated in CdS/CdTe solar cells that the interfacial diffusion reduced interfacial lattice mismatch and defects, then reduced the current loss and improved device efficiency ${ }^{33}$.

Deep defects in VTD- and RTE-fabricated devices. We subsequently investigated the deep defects in $\mathrm{CdS} / \mathrm{Sb}_{2} \mathrm{Se}_{3}$ solar cells fabricated via VTD and RTE processes to demonstrate how the trap-assisted recombination was reduced in VTD-fabricated device. DLTS is a well-accepted powerful tool to investigate defect energy level, type and concentration in thin film photovoltaics $^{14,15,37-40}$. It uses the transient capacitance of $\mathrm{p}-\mathrm{n}$ junction at different temperature as a probe to monitor the changes in charge state of a deep defect center ${ }^{41}$. Traps in the device are filled by carriers through applying a voltage pulse to the device, which changes the capacitance associated with $\mathrm{p}-\mathrm{n}$ junction of the device ${ }^{42}$.

We comparatively analyzed the deep-level defects in VTDfabricated and RTE-fabricated $\mathrm{Sb}_{2} \mathrm{Se}_{3}$ films by DLTS. Herein, we adopted DLTS with minority carriers injection (inj-DLTS) to detect both electron and hole traps in $\mathrm{Sb}_{2} \mathrm{Se}_{3}$ films $37,38,40,43$. As shown in Fig. 5a, during the measurement, a quiescent reverse bias ( $\left.V_{\text {reverse }}\right)$ was first applied to the junction for forming a depletion width in $\mathrm{Sb}_{2} \mathrm{Se}_{3}$ layer. Then, a forward pulse voltage $\left(V_{\text {fill }}\right)$ was applied to fill the traps in the depletion region. If we set $V_{\text {fill }}<0$, the junction was under reverse bias, and there were only holes injected into the depletion region to fill the traps, and only hole traps were detected. If we set $V_{\text {fill }}>$ 0 , under forward bias condition, both electrons and holes were injected into the depletion region, and thus both electron and hole traps could be detected (inj-DLTS) ${ }^{37,38,40}$.

Here, we take the hole traps as an example to elaborate the change of transient capacitance caused by holes capture and emission (Fig. 5a). Figure 5b shows the corresponding variation of depletion width $\left(W_{\mathrm{d}}\right)$ and the process of holes being trapped and emitted, before and after the pulse voltage applied. $C_{0}$ represents the steady-state junction capacitance at $V_{\text {reverse }}$ bias. When $V_{\text {fill }}$ was applied and held for a while, $W_{\mathrm{d}}$ narrowed down to $W_{t 0-}$ and the hole trap defects were filled. Once $V_{\text {fill }}$ pulse relaxed, $W_{\mathrm{d}}$ broadened to $W_{t 0+}$ and capacitance decreased to $C_{t 0}$ + instantaneously. $W_{t 0+}$ was even larger than $W_{0}$ because some holes had been trapped in depletion region. Over the course of time, the trapped holes were gradually and eventually completely emitted from the occupied deep level. Then, $W_{\mathrm{d}}$ shrank to $W_{0}$ and the capacitance returned to steady state $\left(C_{0}\right)$. As the state of activated defects was determined by the temperature, a sequence of transient capacitance was thus measured at different sample temperature, and capacitance changes within a time window vs. the different temperatures was sampled as DLTS signal. We took a fixed time window between $t_{1}$ and $t_{2}$ (Fig. 5a), and then the corresponding hole emission rate $e_{\mathrm{p}}$ can be expressed by Eq. (1): $:^{15}$

$$
e_{\mathrm{p}}=\frac{\ln \left(t_{2} / t_{1}\right)}{t_{2}-t_{1}} \text {. }
$$

As shown in Fig. 5a, the capacitance change within the time window is $\Delta C=C_{t 2}-C_{t 1}$, which depends on the sample temperature. DLTS signal can be reflected from the variation of $\Delta C / C_{0}$ with different sample temperatures. Besides, based on the changing of capacitance during the discharging process of traps, the hole traps and electron traps can be differentiated by positive and negative $\Delta C$, respectively.

DLTS results of VTD-fabricated and RTE-fabricated CdS/ $\mathrm{Sb}_{2} \mathrm{Se}_{3}$ devices are shown in Fig. 5c. One negative and two positive peaks were found in both devices, indicating one electron trap (E1) and two hole trap defects ( $\mathrm{H} 1$ and $\mathrm{H} 2)$ in $\mathrm{Sb}_{2} \mathrm{Se}_{3}$ films. The activation energy and capture cross-section of traps can be obtained from Arrhenius plot based on Eqs. (2) and (3): ${ }^{15,} 38$

$$
\begin{aligned}
& \ln \left(\frac{e_{\mathrm{p}}}{T^{2}}\right)=\ln \left(\sigma_{\mathrm{p}} \frac{16 \pi k_{\mathrm{B}}^{2} m_{\mathrm{p}}^{*}}{h^{3}}\right)-\frac{E_{\mathrm{T}}-E_{\mathrm{V}}}{k_{\mathrm{B}} T}, \\
& \ln \left(\frac{e_{\mathrm{n}}}{T^{2}}\right)=\ln \left(\sigma_{\mathrm{n}} \frac{16 \pi k_{\mathrm{B}}^{2} m_{\mathrm{n}}^{*}}{h^{3}}\right)-\frac{E_{\mathrm{C}}-E_{\mathrm{T}}}{k_{\mathrm{B}} T},
\end{aligned}
$$

where $e_{\mathrm{n}}$ and $e_{\mathrm{p}}$ represents electron and hole emission rate, respectively, which can be obtained by Eq. (1); $\sigma_{\mathrm{p}}$ and $\sigma_{\mathrm{n}}$ are 
a

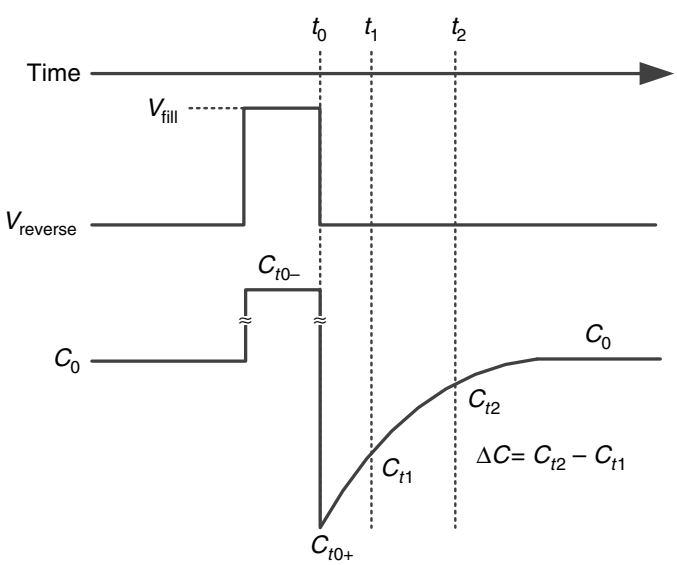

C

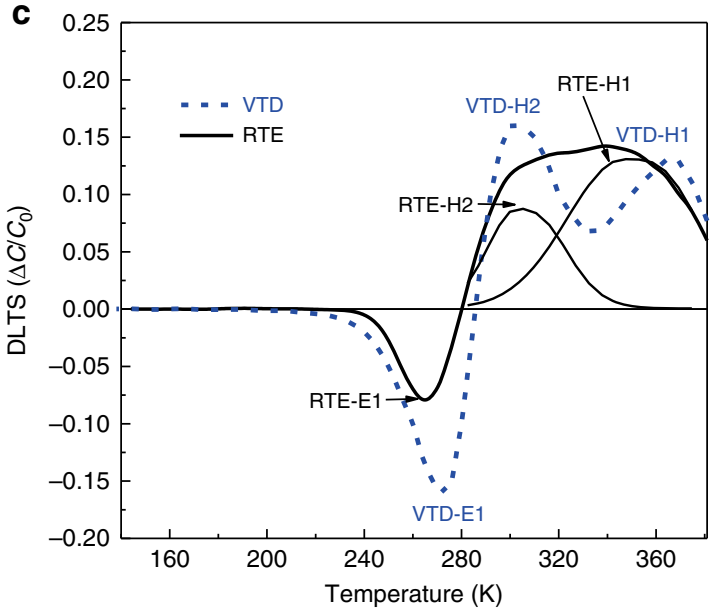

b
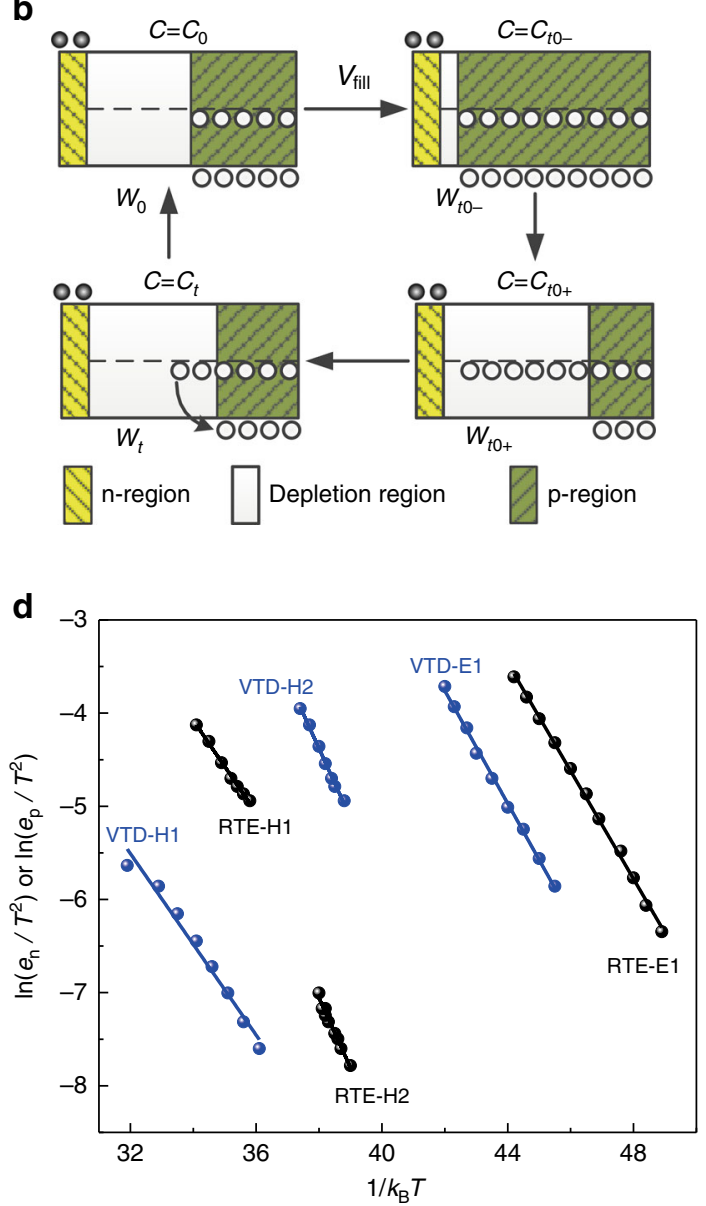

Fig. 5 DLTS analysis of VTD- and RTE-fabricated CdS/Sb $2 \mathrm{Se}_{3}$ solar cells. a Schematic demonstration of the mechanism of DLTS measurement. $\mathbf{b}$ Variation of depletion width and the process of holes being trapped and emitted during the measurement. c DLTS signals of VTD-fabricated and RTE-fabricated devices at $t_{1} / t_{2}=1 \mathrm{~ms} / 10 \mathrm{~ms}$. d Arrhenius plots obtained from DLTS signals. $C_{t 0}$ and $W_{t 0}$ - are the junction capacitance and the depletion width at the moment before pulse voltage ended, respectively. $C_{t 0}$ and $W_{t 0+}$ are the junction capacitance and the depletion width at the moment after pulse voltage ended, respectively

capture cross-section of hole and electron traps, respectively, $T$ is the temperature, and $k_{\mathrm{B}} T$ is the thermal energy. In addition, $m_{\mathrm{p}}{ }^{*}$ and $m_{\mathrm{n}}{ }^{*}$ respectively represent effective mass of hole and electron, and $E_{\mathrm{T}}, E_{\mathrm{C}}$ and $E_{\mathrm{V}}$ are the energy level of defect, conduction and valence bands, respectively. Figure $5 \mathrm{~d}$ shows the Arrhenius plot obtained from Fig. $5 c$, by the varied $e$ (hole or electron emission rate) corresponding to the DLTS peak positions in temperature according to Eqs. (2) and (3). Activation energy $\left(E_{\mathrm{T}}-E_{\mathrm{V}}\right.$ or $E_{\mathrm{C}}$ $\left.-E_{\mathrm{T}}\right)$ of the trap can be calculated from the slope of $\ln \left(e_{\mathrm{p}} / T^{2}\right)$ or $\ln \left(e_{\mathrm{n}} / T^{2}\right)$ vs. $1 / k_{\mathrm{B}} T$ plot, and the capture cross-section could be extracted from the $y$-intercept. The trap concentration $\left(N_{\mathrm{T}}\right)$ can be obtained from the Eq. $(4)^{15,39}$ :

$$
N_{\mathrm{T}}=\frac{2 \Delta C_{\max }}{C_{0}} N_{\mathrm{A}},
$$

here $N_{\mathrm{A}}$ is the net acceptor concentration in $\mathrm{Sb}_{2} \mathrm{Se}_{3}$ film, which can be obtained from $C-V$ profiling (Fig. $4 \mathrm{i}$ ); $\Delta C_{\max }$ equals to the difference between $C_{t 0+}$ and $C_{0}$ (Fig. 5a).

Based on the above fitting results and calculation, the defect parameters of VTD- and RTE-fabricated $\mathrm{Sb}_{2} \mathrm{Se}_{3}$ solar cells are summarized in Table 1. The properties of deep defects in $\mathrm{Sb}_{2} \mathrm{Se}_{3}$ film are experimentally uncovered. By comparing the activation energies of these trap defects, we find that they are similar in both devices, indicating the same origins of these defects. To investigate whether Cd diffusion affects the DLTS results, we

\begin{tabular}{|c|c|c|c|}
\hline Defects & $E_{\mathrm{T}}(\mathrm{eV})$ & $\sigma\left(\mathrm{cm}^{2}\right)$ & $N_{T}\left(\mathrm{~cm}^{-3}\right)$ \\
\hline VTD-H1 & $E_{V}+0.48 \pm 0.07$ & $1.5 \times 10^{-17}$ & $1.2 \times 10^{15}$ \\
\hline VTD-H2 & $E_{V}+0.71 \pm 0.02$ & $4.9 \times 10^{-13}$ & $1.1 \times 10^{14}$ \\
\hline VTD-E1 & $E_{C}-0.61 \pm 0.03$ & $4.0 \times 10^{-13}$ & $2.6 \times 10^{14}$ \\
\hline RTE-H1 & $E_{V}+0.49 \pm 0.03$ & $2.2 \times 10^{-16}$ & $1.2 \times 10^{14}$ \\
\hline RTE-H2 & $E_{V}+0.74 \pm 0.04$ & $7.7 \times 10^{-13}$ & $2.3 \times 10^{15}$ \\
\hline RTE-E1 & $E_{C}-0.60 \pm 0.02$ & $1.6 \times 10^{-12}$ & $1.7 \times 10^{15}$ \\
\hline
\end{tabular}

measured the variation of depletion width with the applied bias, as shown in Supplementary Fig. 8. The depletion width of VTDand RTE-fabricated devices decreased from 430 and $324 \mathrm{~nm}$ to 240 and $255 \mathrm{~nm}$ with the bias pulse changing from $-0.5 \mathrm{~V}$ to 0.4 $\mathrm{V}$, respectively. However, the Cd diffusion depths in VTD- and RTE-fabricated $\mathrm{Sb}_{2} \mathrm{Se}_{3}$ layers are about $200 \mathrm{~nm}$ and $100 \mathrm{~nm}$ from SIMS results, respectively. Thus, the Cd ions located outside the detected depletion region and had no effect on DLTS result. The defects only originate from the intrinsic $\mathrm{Sb}_{2} \mathrm{Se}_{3}$.

In our VTD and RTE facilities, Se vapor is always excess for its higher vapor pressure than $\mathrm{Sb}$ and $\mathrm{Sb}_{2} \mathrm{Se}_{3}$, so the $\mathrm{Sb}_{2} \mathrm{Se}_{3}$ films are actually slightly $\mathrm{Se}_{\text {rich }}{ }^{1,2}$. Our previous ab initio calculation of the intrinsic defects in $\mathrm{Sb}_{2} \mathrm{Se}_{3}$ has demonstrated that the dominant 
a

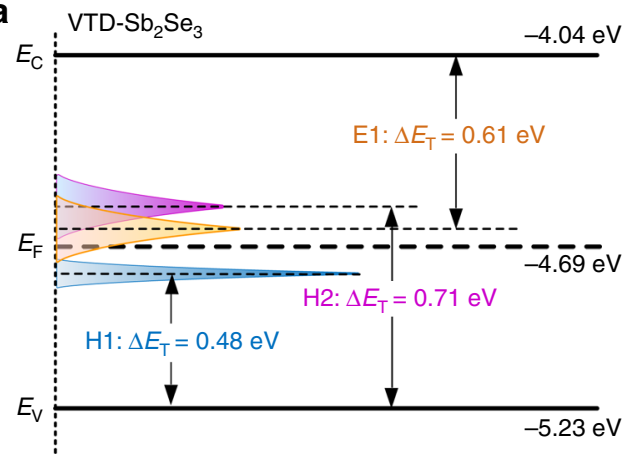

C

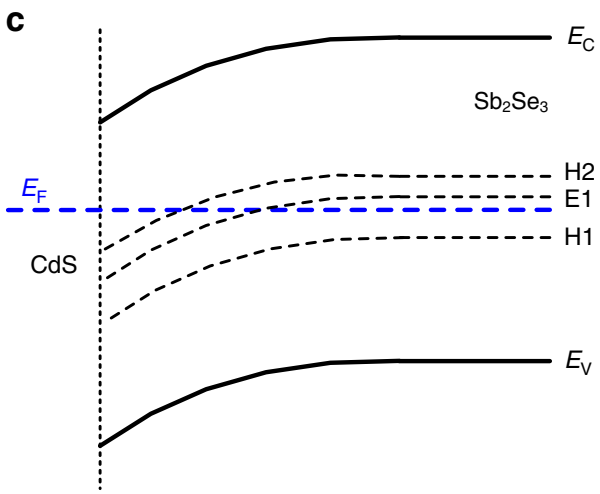

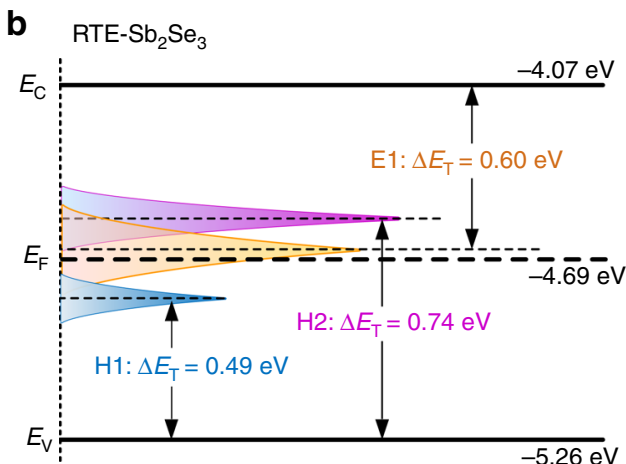

d

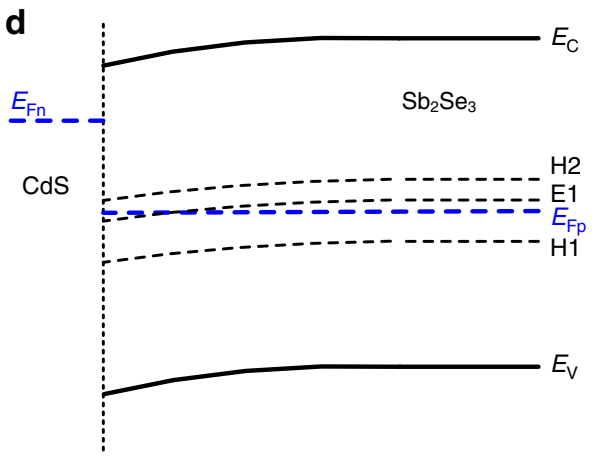

Fig. 6 Influence of defect levels on the $\mathrm{CdS} / \mathrm{Sb}_{2} \mathrm{Se}_{3}$ solar cells. Energy states and defect level of a VTD-fabricated and $\mathbf{b}$ RTE-fabricated $\mathrm{Sb}_{2} \mathrm{Se} \mathrm{f}_{3}$ films. Energy band diagrams at $\mathrm{CdS} / \mathrm{Sb}_{2} \mathrm{Se}_{3}$ interface $\mathbf{c}$ in the dark and $\mathbf{d}$ under illumination

acceptor defects are antimony vacancy $\left(\mathrm{V}_{\mathrm{Sb}}\right)$ and selenium antisite $\left(\mathrm{Se}_{\mathrm{Sb}}\right)$ defects under Se-rich condition ${ }^{11}$. Therefore, we tentatively attributed $\mathrm{H} 1$ and $\mathrm{H} 2$ defects to $\mathrm{V}_{\mathrm{Sb}}$ and $\mathrm{Se}_{\mathrm{Sb}}$ defects, respectively. As reported by Tumelero et al. ${ }^{44}$, the antisite defects dominated the distribution of defects in trichalcogenides due to the similar sizes of the constituent atoms. Our previous simulation also showed that $\mathrm{Se}_{\mathrm{Sb}}$ and antimony antisite $\left(\mathrm{Sb}_{\mathrm{Se}}\right)$ are acceptor and donor defects, respectively ${ }^{11}$. Consequently, the $\mathrm{E} 1$ defect is most likely associated with the formation of $\mathrm{Sb}_{\mathrm{Se}}$ antisite defects. Interestingly, E1 and H2 always have similar densities with each other in both VTD- and RTE-fabricated samples, which indicate that antisite defect pairs formed in $\mathrm{Sb}_{2} \mathrm{Se}_{3}$ films, presumably forming $\left[\mathrm{Sb}_{\mathrm{Se}}+\mathrm{Se}_{\mathrm{Sb}}\right]$ complex. Please also note that using VTD process reduced the density of these antisite defect pairs by more than an order of magnitude (Table 1).

The energy levels of defects in the two samples are depicted in Fig. 6a, b, respectively. Herein, the conduction band, valence band and Fermi levels were obtained from ultraviolet photoelectron spectroscopy (UPS) and Tauc plots by transmission spectra of $\mathrm{Sb}_{2} \mathrm{Se}_{3}$ films (Supplementary Fig. 9). Clearly, the energy levels of $\mathrm{H} 2$ and $\mathrm{E} 1$ are above the Fermi level $\left(E_{\mathrm{F}}\right)$ in both samples, and $\mathrm{H} 1$ is under $E_{\mathrm{F}}$. To analyze the influence of defects on the photogenerated carrier recombination, energy band and defect energy levels of $\mathrm{CdS} / \mathrm{Sb}_{2} \mathrm{Se}_{3}$ device in the dark and under illumination are depicted in Fig. 6c, d, respectively. Due to thermal equilibrium, the energy band of $\mathrm{Sb}_{2} \mathrm{Se}_{3}$ bended downward around the heterointerface, which led to the same Fermi level in CdS and $\mathrm{Sb}_{2} \mathrm{Se}_{3}$ layers. Under illumination, as depicted in Fig. 6d, the photogenerated electrons were driven into CdS layer, prompting electron quasi-Fermi level $\left(E_{\mathrm{Fn}}\right)$ to move upward in CdS. Meanwhile the photo-generated holes resulted in the hole quasi-Fermi level $\left(E_{\mathrm{Fp}}\right)$ shifting downward in $\mathrm{Sb}_{2} \mathrm{Se}_{3}$ layer. The shift of quasi-Fermi levels is positively correlated with the nonequilibrium carrier concentration. The difference between the two quasi-Fermi levels determines $V_{\mathrm{OC}}$ of the solar cell ${ }^{14}$.
We now discuss influence of defects in working conditions. The position of $E_{\mathrm{Fp}}$ is always dependent on illumination intensity, and Fig. $6 \mathrm{~d}$ revealed the situation under AM1.5 irradiation. The intersections of $E_{\mathrm{F}}$ and defect levels can be used as boundaries to differentiate whether the defects are charged or not during the shifting of quasi-Fermi level ${ }^{45}$. Clearly, H1 state is under Fermi level and submersed in electrons, so H1 defects always stay inert. In contrast, $\mathrm{H} 2$ and $\mathrm{E} 1$ defect states are mostly above $E_{\mathrm{F}}$ and they are active in trapping holes and electrons, respectively. These trapped photo-generated carriers would most probably contribute to recombination loss. Furthermore, the energy levels of $\mathrm{H} 2$ and E1 are located near to the midgap, which significantly increase the recombination possibility of photo-generated carriers ${ }^{46}$. Therefore, the $\mathrm{H} 2$ and $\mathrm{E} 1$ are the dominant defects that influence the shift of quasi-Fermi levels and trap-assisted recombination, and then the $V_{\mathrm{OC}}$ and $J_{\mathrm{SC}}$ of the solar cells. Moreover, due to the higher defect density of $\mathrm{H} 2$ and $\mathrm{E} 1$ than carrier concentration (about $10^{13} \mathrm{~cm}^{-3}$ ) in $\mathrm{Sb}_{2} \mathrm{Se}_{3}$ layer ${ }^{3}$, the $E_{\mathrm{Fp}}$ would be more likely to be pinned near E1 and $\mathrm{H} 2$ levels. Obviously, both of $\mathrm{H} 2$ and $\mathrm{E} 1$ have lower defect density in VTD-fabricated sample, which could lead to relatively larger $E_{\mathrm{Fp}}$ downshifting and suppressed trapassisted recombination, explaining the better $V_{\mathrm{OC}}$ and $J_{\mathrm{SC}}$ in VTD-fabricated $\mathrm{Sb}_{2} \mathrm{Se}_{3}$ solar cells.

\section{Discussion}

We have demonstrated that VTD technique can greatly enhance the performance of $\mathrm{Sb}_{2} \mathrm{Se}_{3}$ thin film solar cells by increasing the crystallinity of $\mathrm{Sb}_{2} \mathrm{Se}_{3}$ films, reducing the interface and bulk defects in the devices, and prolonging the carrier lifetime. Specifically, we believe the advantages of VTD over RTE are based on two features. First, the substrate temperature in VTD process can be regulated independently by changing the distance between source and substrate, thus permitting higher substrate temperature (VTD $390^{\circ} \mathrm{C}$ vs. RTE $350^{\circ} \mathrm{C}$ ). The higher substrate temperature resulted in improved crystallinity (threefold enhancement in XRD peak intensity) and 
average grain size (VTD $382 \mathrm{~nm}$ vs. RTE $297 \mathrm{~nm}$ ) of $\mathrm{Sb}_{2} \mathrm{Se}_{3}$ films. Second, the slower deposition of $\mathrm{Sb}_{2} \mathrm{Se}_{3}$ films (VTD 2 min vs. RTE $35 \mathrm{~s})$ enables less film imperfection $\left(\mathrm{Se}_{\mathrm{Sb}}+\mathrm{Se}_{\mathrm{sb}}\right.$ antisite complex and $\mathrm{V}_{\mathrm{Sb}}$ vacancy), as reflected by the reduced bulk defect density (VTD $10^{14} \mathrm{~cm}^{-3}$ vs. RTE $10^{15} \mathrm{~cm}^{-3}$ ) and interfacial defect density (VTD $2.8 \times 10^{10} \mathrm{~cm}^{-2}$ vs. RTE $\left.2.1 \times 10^{11} \mathrm{~cm}^{-2}\right)$, and increased carrier lifetime (VTD 1339 ps vs. 1149 ps). Overall, all these advantages facilitated the fabrication of high-quality $\mathrm{Sb}_{2} \mathrm{Se}_{3}$ films, leading to increased $V_{\mathrm{OC}}$, $J_{\mathrm{SC}}$ as well as FF (VTD: $0.42 \mathrm{~V}, 29.9 \mathrm{~mA} \mathrm{~cm}^{-2}, 60.4 \%$ vs. RTE: $\left.0.39 \mathrm{~V}, 25.3 \mathrm{~mA} \mathrm{~cm}^{-2}, 56.4 \%\right)$. The champion device achieved the efficiency record $7.6 \%$, much higher than $\mathrm{SnS}, \mathrm{Cu}_{2} \mathrm{O}$ and $\mathrm{FeS}_{2}$ solar cells which have been studied for many years ${ }^{47-49}$. The fabrication of record efficiency $\mathrm{Sb}_{2} \mathrm{Se}_{3}$ solar cells employing vapor transport deposition, a technique with proven high turnaround and low cost for commercial CdTe solar cells, further strengthens the great potential of our $\mathrm{Sb}_{2} \mathrm{Se}_{3}$ thin film photovoltaics.

On the other hand, we find that the deep defect density in the best-performing $\mathrm{Sb}_{2} \mathrm{Se}_{3}$ solar cells is about $10^{14}$ to $10^{15} \mathrm{~cm}^{-3}$, which is much higher than that $\left(10^{11}\right.$ to $\left.10^{13} \mathrm{~cm}^{-3}\right)$ in CdTe solar cells $^{50}$. These abundant deep defects could pin the quasi-Fermi level near $\mathrm{H} 2$ and $\mathrm{E} 1$ defect states, which provides a plausible explanation for the low $V_{\mathrm{OC}}$ observed in all $\mathrm{Sb}_{2} \mathrm{Se}_{3}$ solar cells reported so far, despite various device configuration and film preparation methods have been explored ${ }^{1-12,19,32,51}$. We suggest that future research on tightly controlling Se and Sb components in the vapor, their strictly stoichiometric condensation into the film and the growth of highly crystalline film should be carried out to minimize these deep defects and maximize device performance.

In summary, we have obtained the superstrate $\mathrm{CdS} / \mathrm{Sb}_{2} \mathrm{Se}_{3}$ thin film solar cell with a certified efficiency of $7.6 \%\left(V_{\mathrm{OC}}\right.$ of $0.42 \mathrm{~V}$, $J_{\mathrm{SC}}$ of $29.9 \mathrm{~mA} \mathrm{~cm}^{-2}$ and $\mathrm{FF}$ of $60.4 \%$ ), which was promoted by the VTD-fabricated $\mathrm{Sb}_{2} \mathrm{Se}_{3}$ absorber layer. Compared with the previous reports on $\mathrm{Sb}_{2} \mathrm{Se}_{3}$ solar cells ${ }^{1-6,8-12,19,20}$, VTD process reduced the density of deep defects and subsequently suppressed trap-assisted recombination in $\mathrm{Sb}_{2} \mathrm{Se}_{3}$ films, resulting in longer carrier lifetime and better device performance. These encouraging results highlight the potential of $\mathrm{Sb}_{2} \mathrm{Se}_{3}$ solar cells for highefficiency photovoltaic devices.

\section{Methods}

$\mathbf{S b}_{\mathbf{2}} \mathbf{S e}_{\mathbf{3}}$ solar cell fabrication. All solar cells were deposited on ITO $\left(\mathrm{In}_{2} \mathrm{O}_{3}: \mathrm{Sn}\right)$ transparent conductive glass supplied by Kaivo, with sheet resistance of 6.5 to 6.8 $\mathrm{ohm} \mathrm{sq}{ }^{-1}$, transmittance of 78.8 to $79.6 \%$ and ITO thickness of about $200 \mathrm{~nm}$. The ITO substrates were cleaned using detergent, acetone, isopropanol, ethanol and deionized water in sequence. CdS buffer layer was deposited by chemical bath deposition ${ }^{7}$. CdS layers were treated with $\mathrm{H}_{2} \mathrm{O}_{2}(30 \mathrm{wt} \%)$ and $20 \mathrm{mg} \mathrm{ml}^{-1} \mathrm{CdCl}_{2}$ (Aladdin) absolute methanol solution by spin coating, respectively, baked on the hotplate at $400^{\circ} \mathrm{C}$ for $5 \mathrm{~min}$ in air ambient and then cooled down naturally. Following that, VTD process was used to deposit $\mathrm{Sb}_{2} \mathrm{Se}_{3}$ films. As shown in Fig. 1a, $0.25 \mathrm{~g} \mathrm{Sb}_{2} \mathrm{Se}_{3}$ powder (99.999\% purity, Jiangxi Ketai) was put into a quartz crucible and placed in the center of VTD system (a single temperature zone tube furnace, MTI, Hefei, China). The ITO/CdS substrate was immobilized on a graphite support and then placed at the right end of the quartz tube. Substrate temperature was regulated by changing the distance between substrate and the center of the heater. Vacuum was pumped by a mechanical pump and the stabilized chamber pressure was controlled by varying the ventilation power of the pump. The heating temperature of VTD system was raised to the targeted evaporation temperature with a ramp rate of $20^{\circ} \mathrm{C} \mathrm{min}^{-1}$ and kept for 2 min to obtain a desired $\mathrm{Sb}_{2} \mathrm{Se}_{3}$ film thickness. Then, we turned off the power to stop the deposition and finally took the sample out when it was naturally cooled down to about $100^{\circ} \mathrm{C}$. After that, gold back-contact electrodes $\left(0.091 \mathrm{~cm}^{2}\right.$ area, $100 \mathrm{~nm}$ thick) were evaporated by the resistance evaporation thin film system (Beijing Technol Science) under a vacuum pressure of $5 \times 10^{-3} \mathrm{~Pa}$. To optimize the quality of $\mathrm{Sb}_{2} \mathrm{Se}_{3}$ film and the performance of device, we systematically investigated the evaporation temperature of VTD system from 480 to $520^{\circ} \mathrm{C}$, the pressure from 2.8 to $5.3 \mathrm{~Pa}$ and the substrate distance from 19 to $23 \mathrm{~cm}$. When the evaporation temperature was investigated, the pressure and the distance were set as $4 \mathrm{~Pa}$ and $22 \mathrm{~cm}$, respectively. The optimized evaporation temperature and the distance of $22 \mathrm{~cm}$ were adopted for pressure investigation, and then the optimized temperature and pressures were used to investigate the substrate distance.
Material characterization. Material and device characterization are similar to previous report ${ }^{1,2,11}$. XRD of $\mathrm{Sb}_{2} \mathrm{Se}_{3}$ films was performed using a Philips X'Pert Pro diffractometer with $\mathrm{Cu} \mathrm{Ka}$ radiation $(\lambda=1.54 \AA$ ). SEM measurement was carried out with FEI Nova Nano SEM450. SIMS (IMS-4f, CAMECA instruments) was used to investigate the element distribution along the depth in the devices. UPS was used to investigate the Fermi level and valence band of $\mathrm{Sb}_{2} \mathrm{Se}_{3}$ films. Experiments were performed using a He I $(21.21 \mathrm{eV})$ gas discharge lamp in a Kratos AXIS-ULTRA DLD-600W x-ray photoelectron spectroscopy measurement system and recorded at $0 \mathrm{~V}$ samples bias in an ultrahigh vacuum chamber. The surface of $\mathrm{Sb}_{2} \mathrm{Se}_{3}$ films was etched before UPS measurement. Ultraviolet-visible near-infrared transmission spectra (Perkin Elmer Instrument, Lambda 950 using integrating sphere) were measured to determine the bandgap of $\mathrm{Sb}_{2} \mathrm{Se}_{3}$ films.

Device characterization. $J-V$ curve and PCE of the champion $\mathrm{CdS} / \mathrm{Sb}_{2} \mathrm{Se}_{3}$ solar cell was independently measured by National Institute Metrology (NIM), using the Class AAA Solar Simulator with double-light source (SAN-EI ELECTRIC, XHS$2350 \mathrm{M} 1,100 \mathrm{~mW} \mathrm{~cm}^{-2}$, AM1.5 illumination) in air ambient at room temperature. A metal mask was used to define the area of incident light. The area $\left(9.099 \mathrm{~mm}^{2}\right)$ was also measured by NIM. The light intensity was calibrated by a standard Sireference solar cell. A Keithley 2400 Source Meter was used to acquire $J-V$ data. The external quantum efficiency of solar cells was measured using the light source generated by a $300 \mathrm{~W}$ xenon lamp of Newport (Oriel, 69911) and then split into specific wavelengths by a Newport Oriel Cornerstone 130 1/8 Monochromator (Oriel, model 74004). A standard silicon detector (70356_70316NS_455) was used for the calibration. The capacitance-voltage $(C-V)$ profiling and DLCP data were measured using Keithley 4200. $C$ - $V$ measurements were performed at room temperature in an electromagnetic shielding box at a frequency of $100 \mathrm{kHz}$ and a.c. amplitude of $30 \mathrm{mV}$. The d.c. bias voltage was scanned from $-1.0 \mathrm{~V}$ to $0.3 \mathrm{~V}$. DLCP measurements were performed with a.c. amplitude from $0.02 \mathrm{~V}$ to $0.14 \mathrm{~V}$ and d.c. bias voltage from $-0.2 \mathrm{~V}$ to $0.2 \mathrm{~V}$. DLTS measurement were performed by Semetrol DLTS system (Semetrol, LLC, USA) on the two typical devices. The temperature was scanned between 100 and $380 \mathrm{~K}$, at a heating rate of $2 \mathrm{~K} \mathrm{~min}^{-1}$ The reverse bias voltage was $-0.5 \mathrm{~V}$. The filling pulse voltage and width were $0.4 \mathrm{~V}$ and $1 \mathrm{~ms}$, respectively. At every scanning temperature point, the transient capacitance was measured 20 times for obtaining the average value. Transient absorption spectroscopy was pumped by $500 \mathrm{~nm}$ laser pulses (Light Conversion, Pharos, $350 \mathrm{fs}$ duration pulses, $5 \mathrm{kHz}$ repetition rate) and probed at $940 \mathrm{~nm}$. The time delay was adjusted by changing the path length of the probe.

Data availability. The data that support the findings of this study are available from the corresponding author on request.

Received: 22 December 2017 Accepted: 19 April 2018 Published online: 05 June 2018

\section{References}

1. Wang, L. et al. Stable 6\%-efficient $\mathrm{Sb}_{2} \mathrm{Se}_{3}$ solar cells with a $\mathrm{ZnO}$ buffer layer. Nat. Energy 2, 17046 (2017).

2. Zhou, Y. et al. Thin-film $\mathrm{Sb}_{2} \mathrm{Se}_{3}$ photovoltaics with oriented one-dimensional ribbons and benign grain boundaries. Nat. Photon. 9, 409-415 (2015).

3. Chen, C. et al. Characterization of basic physical properties of $\mathrm{Sb}_{2} \mathrm{Se}_{3}$ and its relevance for photovoltaics. Front. Optoelectron. 10, 18-30 (2017).

4. Liu, X. et al. Thermal evaporation and characterization of $\mathrm{Sb}_{2} \mathrm{Se}_{3}$ thin film for substrate $\mathrm{Sb}_{2} \mathrm{Se}_{3} / \mathrm{CdS}$ solar cells. ACS Appl. Mater. Interfaces 6, 10687-10695 (2014).

5. Leng, M. et al. Selenization of $\mathrm{Sb}_{2} \mathrm{Se}_{3}$ absorber layer: an efficient step to improve device performance of $\mathrm{CdS} / \mathrm{Sb}_{2} \mathrm{Se}_{3}$ solar cells. Appl. Phys. Lett. 105, 083905 (2014)

6. Luo, M. et al. Thermal evaporation and characterization of superstrate CdS/ $\mathrm{Sb}_{2} \mathrm{Se}_{3}$ solar cells. Appl. Phys. Lett. 104, 173904 (2014).

7. Wang, L. et al. Ambient $\mathrm{CdCl}_{2}$ treatment on CdS buffer layer for improved performance of $\mathrm{Sb}_{2} \mathrm{Se}_{3}$ thin film photovoltaics. Appl. Phys. Lett. 107, 143902 (2015).

8. Liu, X. et al. Improving the performance of $\mathrm{Sb}_{2} \mathrm{Se}_{3}$ thin film solar cells over $4 \%$ by controlled addition of oxygen during film deposition. Prog. Photo. Res. Appl. 23, 1828-1836 (2015).

9. $\mathrm{Li}, \mathrm{Z}$. et al. $\mathrm{Sb}_{2} \mathrm{Se}_{3}$ thin film solar cells in substrate configuration and the back contact selenization. Sol. Energy Mater. Sol. Cells 161, 190-196 (2017).

10. Yuan, C., Jin, X., Jiang, G., Liu, W. \& Zhu, C. $\mathrm{Sb}_{2} \mathrm{Se}_{3}$ solar cells prepared with selenized dc-sputtered metallic precursors. J. Mater. Sci. Mater. Electron 27, 8906-8910 (2016)

11. Liu, X. et al. Enhanced $\mathrm{Sb}_{2} \mathrm{Se}_{3}$ solar cell performance through theory-guided defect control. Prog. Photo. Res. Appl. 25, 861-870 (2017).

12. Chen, C. et al. $6.5 \%$ certified $\mathrm{Sb}_{2} \mathrm{Se}_{3}$ solar cells using $\mathrm{PbS}$ colloidal quantum dot film as hole transporting layer. ACS Energy Lett. 2, 2125-2132 (2017). 
13. Leijtens, T. et al. Carrier trapping and recombination: the role of defect physics in enhancing the open circuit voltage of metal halide perovskite solar cells. Energy Environ. Sci. 9, 3472-3481 (2016).

14. Heo, S. et al. Deep level trapped defect analysis in $\mathrm{CH}_{3} \mathrm{NH}_{3} \mathrm{PbI}_{3}$ perovskite solar cells by deep level transient spectroscopy. Energy Environ. Sci. 10, 1128-1133 (2017).

15. Lang, D. V. Deep-level transient spectroscopy: a new method to characterize traps in semiconductors. J. Appl. Phys. 45, 3023-3032 (1974).

16. Yang, W. S. et al. Iodide management in formamidinium-lead-halide-based perovskite layers for efficient solar cells. Science 356, 1376-1379 (2017).

17. Kestner, J. M. et al. An experimental and modeling analysis of vapor transport deposition of cadmium telluride. Sol. Energy Mater. Sol. Cells 83, 55-65 (2004).

18. Wangperawong, A. et al. Bifacial solar cell with $\mathrm{SnS}$ absorber by vapor transport deposition. Appl. Phys. Lett. 105, 173904 (2014).

19. Ngo, T. T. et al. Electrodeposition of antimony selenide thin films and application in semiconductor sensitized solar cells. ACS Appl. Mater. Interfaces 6, 2836-2841 (2014).

20. Choi, Y. C. et al. $\mathrm{Sb}_{2} \mathrm{Se}_{3}$-Sensitized inorganic-organic heterojunction solar cells fabricated using a single-source precursor. Angew. Chem. Int. Ed. 53, 1329-1333 (2014).

21. Mattox, D. M. Particle bombardment effects on thin-film deposition: A review. J. Vac. Sci. Technol. A 7, 1105-1114 (1989).

22. Rossnagel, S. M. Thin film deposition with physical vapor deposition and related technologies. J. Vac. Sci. Technol. A 21, S74-S87 (2003).

23. Lin, X. Z. et al. $11.3 \%$ efficiency $\mathrm{Cu}(\mathrm{In}, \mathrm{Ga})(\mathrm{S}, \mathrm{Se})_{2}$ thin film solar cells via dropon-demand inkjet printing. Energy Environ. Sci. 9, 2037-2043 (2016).

24. Quilettes, D. W. et al. Impact of microstructure on local carrier lifetime in perovskite solar cells. Science 348, 683-686 (2015).

25. Sun, Z. H., Sitbon, G., Pons, T., Bakulin, A. A. \& Chen, Z. Y. Reduced carrier recombination in $\mathrm{PbS}-\mathrm{CuInS}_{2}$ quantum dot solar cells. Sci. Rep. 5, 10626 (2015).

26. Zhao, B. D. et al. High open-circuit voltages in Tin-rich low-bandgap perovskite-based planar heterojunction photovoltaics. Adv. Mater. 29, 1604744 (2017).

27. Gao, F. et al. Trap-induced losses in hybrid photovoltaics. ACS Nano. 8, 3213-3221 (2014)

28. Abbaszadeh, D. et al. Elimination of charge carrier trapping in diluted semiconductors. Nat. Mater. 15, 628-633 (2016).

29. Szendrei, K., Gomulya, W., Yarema, M., Heiss, W. \& Loi, M. A. PbS nanocrystal solar cells with high efficiency and fill factor. Appl. Phys. Lett. 97, 203501 (2010)

30. Li, Y. W. et al. High-efficiency robust perovskite solar cells on ultrathin flexible substrates. Nat. Commun. 7, 10214 (2016).

31. Jahandar, $\mathrm{M}$. et al. Highly efficient metal halide substituted $\mathrm{CH}_{3} \mathrm{NH}_{3} \mathrm{I}\left(\mathrm{PbI}_{2}\right)_{1}$. ${ }_{x}\left(\mathrm{CuBr}_{2}\right)_{\mathrm{x}}$ planar perovskite solar cells. Nano Energy 27, 330-339 (2016).

32. Zhou, Y. et al. Buried homojunction in $\mathrm{CdS} / \mathrm{Sb}_{2} \mathrm{Se}_{3}$ thin film photovoltaics generated by interfacial diffusion. Appl. Phys. Lett. 111, 013901 (2017).

33. Kumar, S. G. \& Rao, K. S. R. K. Physics and chemistry of CdTe/CdS thin film heterojunction photovoltaic devices: fundamental and critical aspects. Energy Environ. Sci. 7, 45-102 (2014).

34. Liu, F. Y. et al. Nanoscale microstructure and chemistry of $\mathrm{Cu}_{2} \mathrm{ZnSnS}_{4} / \mathrm{CdS}$ interface in Kesterite $\mathrm{Cu}_{2} \mathrm{ZnSnS}_{4}$ solar cells. Adv. Energy Mater. 6, 1600706 (2016).

35. Heath, J. T., Cohen, J. D. \& Shafarman, W. N. Bulk and metastable defects in $\mathrm{CuIn}_{1-\mathrm{x}} \mathrm{Ga}_{\mathrm{x}} \mathrm{Se}_{2}$ thin films using drive-level capacitance profiling. J. Appl. Phys. 95, 1000-1010 (2004).

36. Duan, H. S. et al. The role of sulfur in solution-processed $\mathrm{Cu}_{2} \mathrm{ZnSn}(\mathrm{S}, \mathrm{Se})_{4}$ and its effect on defect properties. Adv. Funct. Mater. 23, 1466-1471 (2013).

37. Auret, F. D. \& Nel, M. Detection of minority-carrier defects by deep level transient spectroscopy using Schottky barrier diodes. J. Appl. Phys. 61, 2546-2549 (1987).

38. Fourches, N. A quantitative treatment for deep level transient spectroscopy under minority-carrier injection. J. Appl. Phys. 70, 209-214 (1991).

39. Kerr, L. L. et al. Investigation of defect properties in $\mathrm{Cu}(\mathrm{In}, \mathrm{Ga}) \mathrm{Se}_{2}$ solar cells by deep-level transient spectroscopy. Solid-State Electron 48, 1579-1586 (2004).

40. Fleming, R. M., Seager, C. H., Lang, D. V. \& Campbell, J. M. Injection deep level transient spectroscopy: An improved method for measuring capture rates of hot carriers in semiconductors. J. Appl. Phys. 118, 015703 (2015).

41. Khan, A. et al. DLTS: A promising technique for the identification of the recombination and compensator centers in solar cell materials. 1763-1768 (Conference Record of the 2006 IEEE 4th World Conference on Photovoltaic Energy Conversion, Waikoloa, 2006).

42. Nguyen, T. P. Defects in organic electronic devices. Phys. Stat. Sol. (a) 205, 162-166 (2008).
43. Dharmarasu, N. et al. Majority- and minority-carrier deep level traps in proton-irradiated n+/p-InGaP space solar cells. Appl. Phys. Lett. 81, 64-66 (2002).

44. Tumelero, M. A., Faccio, R. \& Pasa, A. A. Unraveling the native conduction of trichalcogenides and its ideal band alignment for new photovoltaic interfaces. J. Phys. Chem. C 120, 1390-1399 (2016).

45. Boix, P. P. et al. Determination of gap defect states in organic bulk heterojunction solar cells from capacitance measurements. Appl. Phys. Lett. 95, 233302 (2009)

46. Sherkar, T. S. et al. Recombination in perovskite solar cells: significance of grain boundaries, interface traps, and defect ions. ACS Energy Lett. 2, 1214-1222 (2017).

47. Sinsermsuksakul, P. et al. Overcoming efficiency limitations of SnS-Based solar cells. Adv. Energy Mater. 4, 1400496 (2014).

48. Minami, T., Nishi, Y. \& Miyata, T. Heterojunction solar cell with $6 \%$ efficiency based on an n-type aluminum-gallium-oxide thin film and p-type sodiumdoped $\mathrm{Cu}_{2} \mathrm{O}$ sheet. Appl. Phys. Express 8, 022301 (2015).

49. Prabukanthan, P., Thamaraiselvi, S. \& Harichandranb, G. Single step electrochemical deposition of p-type undoped and $\mathrm{Co}^{2+}$ doped $\mathrm{FeS}_{2}$ thin films and performance in heterojunction solid solar cells. J. Electrochem. Soc. 164, D581-D589 (2017)

50. Versluys, J., Clauws, P., Nollet, P., Degrave, S. \& Burgelman, M. Characterization of deep defects in CdS/CdTe thin film solar cells using deep level transient spectroscopy. Thin Solid Films 451-452, 434-438 (2004).

51. Liang, G. X. et al. Thermally induced structural evolution and performance of $\mathrm{Sb}_{2} \mathrm{Se}_{3}$ films and nanorods prepared by an easy sputtering method. Sol. Energy Mater. Sol. Cells 174, 263-270 (2018).

\section{Acknowledgements}

This work was financially supported by the Major State Basic Research Developmen Program of China (2016YFA0204000), the National Natural Science Foundation of China (61725401, 91433105 and 51602114), the Special Fund for Strategic New Development of Shenzhen, China (JCYJ20160414102210144), and the Project funded by China Postdoctoral Science Foundation (2017M622445). The authors thank the Analytical and Testing Center of HUST and the facility support of the Center for Nanoscale Characterization and Devices, WNLO. We also thank J. Luo and J. Li for X-ray diffraction measurements, Q. Hu for his help in SEM measurements, and Y. Zhong and S. Sun from Zhengzhou University for their help in DLTS measurements.

\section{Author contributions}

X.W. and J.T. conceived the idea, designed the experiments and analyzed the data. X.W., C.C., and S.L. carried out the device optimizations. Y.Z. prepared the gold electrodes. X. W. carried out most of material and device characterizations. L.G. carried out the TA characterization. C.C., S.L., K.L., W.C., R.K., C.W., J.Z. and G.N. assisted in data analysis. X.W. and J.T wrote the paper. All authors commented on the manuscript.

\section{Additional information}

Supplementary Information accompanies this paper at https://doi.org/10.1038/s41467018-04634-6.

Competing interests: The authors declare no competing interests.

Reprints and permission information is available online at http://npg.nature.com/ reprintsandpermissions/

Publisher's note: Springer Nature remains neutral with regard to jurisdictional claims in published maps and institutional affiliations.

Open Access This article is licensed under a Creative Commons Attribution 4.0 International License, which permits use, sharing, adaptation, distribution and reproduction in any medium or format, as long as you give appropriate credit to the original author(s) and the source, provide a link to the Creative Commons license, and indicate if changes were made. The images or other third party material in this article are included in the article's Creative Commons license, unless indicated otherwise in a credit line to the material. If material is not included in the article's Creative Commons license and your intended use is not permitted by statutory regulation or exceeds the permitted use, you will need to obtain permission directly from the copyright holder. To view a copy of this license, visit http://creativecommons.org/ licenses/by/4.0/.

(C) The Author(s) 2018 